\title{
Pregabalin for the treatment of postoperative pain: results from three controlled trials using different surgical models
}

This article was published in the following Dove Press journal: Journal of Pain Research

23 December 2014

Number of times this article has been viewed

\author{
Neil K Singla' \\ Jacques E Chelly ${ }^{2}$ \\ David R Lionberger ${ }^{3}$ \\ Joseph Gimbel ${ }^{4}$ \\ Luis Sanin ${ }^{5}$ \\ Jonathan Sporn ${ }^{5}$ \\ Ruoyong Yang 5 \\ Raymond Cheung ${ }^{5}$ \\ Lloyd Knapp ${ }^{6}$ \\ Bruce Parsons ${ }^{5}$ \\ 'Lotus Clinical Research, Pasadena, \\ CA, USA; ${ }^{2}$ Division of Acute \\ Interventional Perioperative Pain, \\ Department of Anesthesiology, \\ University of Pittsburgh Medical \\ Center, Pittsburgh, PA, USA; \\ ${ }^{3}$ Department of Orthopedic Surgery, \\ Baylor College of Medicine, Houston, \\ TX, USA; ${ }^{4}$ Arizona Research Center, \\ Phoenix, AZ, USA; ${ }^{5}$ Pfizer Inc., New \\ York, NY, USA; ${ }^{6}$ Pfizer Inc., New \\ London, CT, USA
}

Purpose: To evaluate the efficacy and safety of pregabalin (150 or $300 \mathrm{mg} / \mathrm{d}$ ) as an adjunctive therapy for the treatment of postoperative pain.

Patients and methods: This study reports findings from three separate, multicenter, randomized, double-blind, placebo-controlled trials of adjunctive pregabalin for the treatment of postoperative pain. Patients underwent one of three categories of surgical procedures (one procedure per study): elective inguinal hernia repair (post-IHR); elective total knee arthroplasty (post-TKA); or total abdominal hysterectomy (posthysterectomy). The primary endpoint in each trial, mean worst pain over the past 24 hours, was assessed 24 hours post-IHR and posthysterectomy, and 48 hours post-TKA. Patients rated their pain on a scale from 0 to 10 , with higher scores indicating greater pain severity.

Results: In total, 425 (post-IHR), 307 (post-TKA), and 501 (posthysterectomy) patients were randomized to treatment. There were no statistically significant differences between the pregabalin and placebo groups with respect to the primary endpoint in any of the three trials. The least squares mean difference in worst pain, between $300 \mathrm{mg} / \mathrm{d}$ pregabalin and placebo, was -0.7 (95\% confidence interval $[\mathrm{CI}]=-1.4,-0.1$; Hochberg adjusted $P=0.067)$ post-IHR; $-0.34(95 \% \mathrm{CI}=-1.07,0.39 ; P=0.362)$ post-TKA; and $-0.2(95 \% \mathrm{CI}=-0.66,0.31$; $P=0.471$ ) posthysterectomy.

Conclusion: There were no significant differences between pregabalin and placebo with respect to the primary pain intensity measure in each of the three clinical trials. These studies encompass a large dataset (1,233 patients in total), and their results should be considered when assessing pregabalin's effectiveness in postoperative pain. Further studies are required to determine the potential pain-reducing benefit of pregabalin in the postoperative setting.

Keywords: arthroplasty, herniorrhaphy, hysterectomy, postoperative pain, pregabalin

\section{Introduction}

Pregabalin is an $\alpha_{2} \delta$ ligand that modulates the activity of voltage-gated calcium channels. In the US, pregabalin is indicated for the treatment of neuropathic pain associated with diabetic peripheral neuropathy, with spinal cord injury, postherpetic neuralgia, fibromyalgia, and as an adjunctive therapy for adult patients with partial onset seizures. ${ }^{1}$ In the European Union, pregabalin is indicated for peripheral and central neuropathic pain, epilepsy, and generalized anxiety disorder. ${ }^{2}$

There are several positive reports for $\alpha_{2} \delta$ compounds, including pregabalin, for the management of postoperative pain in a variety of surgical models. ${ }^{3-9}$ However, these studies were conducted at single investigational sites and, often, assessed pregabalin in combination with other nonopioid analgesics. Additionally, there have
Correspondence: Neil K Singla

Huntington Hospital, 100 W California Boulevard, Pasadena, CA 91105, USA

Tel +l 6263973507

Fax + I 6266283422

Email neil@lotuscr.com (c) (i) (5) 2015 Singla et al. This work is published by Dove Medical Press Limited, and licensed under Creative Commons Attribution - Non Commercial (unported, v3.0) License. The full terms of the License are available at http://creativecommons.org/licenses/by-nc/3.0/. Non-commercial uses of the work are permitted without any further permission how to request permission may be found at: http://www.dovepress.com/permissions.php 
been reports of negative outcomes in postoperative trials with pregabalin, and the overall benefit of pregabalin in this setting is unclear. ${ }^{10-12}$

To further examine the safety and efficacy of pregabalin in the postoperative setting, three separate, large, multicenter, randomized, placebo-controlled trials of pregabalin as an adjunctive treatment for postoperative pain were conducted in patients following inguinal hernia repair (post-IHR), following total knee arthroplasty (post-TKA), or following hysterectomy (posthysterectomy). Here we report, for the first time, findings from these three trials.

Although the primary endpoint in each of these trials was not met, results from each trial are reported herein in order to contribute to a more balanced, evidence-based assessment of the efficacy of pregabalin for the treatment of postoperative pain.

\section{Patients and methods}

Each of the three trials was a multicenter, randomized, doubleblind, placebo-controlled study. All protocols adhered to the International Conference on Harmonization Good Clinical Practice Guidelines and were reviewed and approved by Institutional Review Boards at participating sites. All patients provided written informed consent prior to participation.

In all three trials, investigators used the sponsor's interactive response technology system (via phone or Internet) to screen, randomize, and assign treatment to patients in a double-blinded manner. Pregabalin and placebo were administered as gray capsules identical in appearance. Patients were assigned a subject identification number at screening and a separate number at randomization to identify which treatment was to be received.

\section{Post-IHR trial}

\section{Patients}

The post-IHR trial was conducted at 34 sites in Australia, Canada, India, Spain, Sweden, and the US between January 2008 and September 2009 (NCT00551135). Patients were males aged 18-75 years undergoing primary, elective, open, unilateral inguinal herniorrhaphy using Lichtenstein mesh repair under general anesthesia. Patients with emergency surgery, hernia incarceration, and those undergoing additional procedures at the time of the total inguinal herniorrhaphy were excluded.

\section{Treatment}

Patients were randomized via a computer-generated $1: 1: 1: 1$ ratio to one of four arms: oral pregabalin $50 \mathrm{mg} / \mathrm{d}(25 \mathrm{mg}$ twice daily [bid]), $150 \mathrm{mg} / \mathrm{d}$ (75 mg bid), or $300 \mathrm{mg} / \mathrm{d}$ (150 mg bid); or placebo (bid). Patients received two preoperative treatment doses at 12 hours and 2 hours before surgery and continued treatment (bid dosing) for 1 week post-IHR (Figure 1). Details of rescue medications allowed are shown in Table 1.

\section{Efficacy outcome measures}

The primary efficacy measure was mean worst pain over the past 24 hours, assessed 24 hours post-IHR. Patients rated their pain using the modified Brief Pain Inventory-short form (mBPI-sf) numeric rating scale (NRS) from $0=$ no pain to $10=$ pain as bad as you can imagine.

Secondary measures of pain included worst, average, and current pain intensity assessed 72 hours post-IHR and severity of movement-induced pain (sitting, walking, or coughing) assessed at 1, 2, and 48 hours post-IHR. Continued pain in the area of surgery was assessed by telephone at 1 , 3 , and 6 months post-IHR. Patients who reported continued
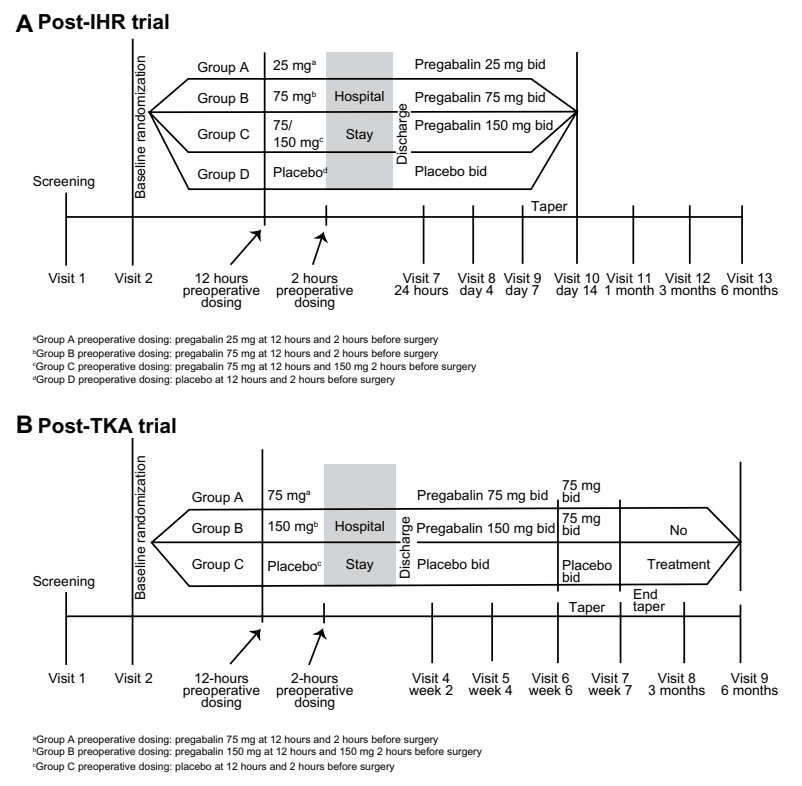

C Posthysterectomy trial

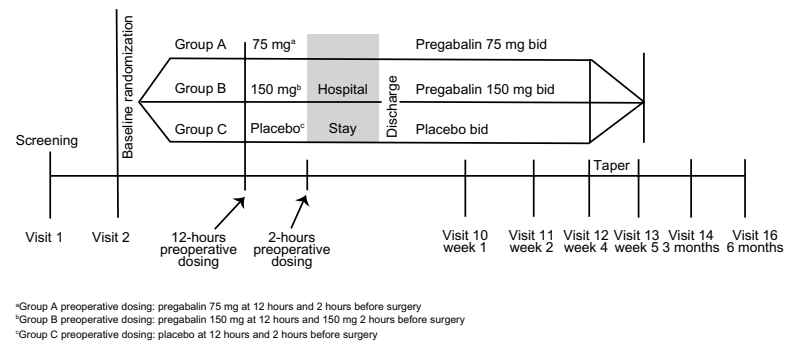

Figure I Design of the three clinical trials.

Abbreviations: bid, twice daily; IHR, inguinal hernia repair; TKA, total knee arthroplasty. 
Table I Details of permitted preoperative, intraoperative, and postoperative anesthesia and analgesia techniques

\begin{tabular}{|c|c|c|c|}
\hline & Preoperative & Intraoperative & Postoperative \\
\hline Post-IHR & $\begin{array}{l}\text { Premedication immediately } \\
\text { prior to surgery included } \\
\text { midazolam or temazepam, as } \\
\text { needed. Patients could } \\
\text { receive propofol for } \\
\text { induction and sevoflurane, } \\
\text { isoflurane, or desflurane. }\end{array}$ & $\begin{array}{l}\text { Intraoperative analgesia was } \\
\text { managed with fentanyl or } \\
\text { sufentanil, as needed. Muscle } \\
\text { relaxants were allowed during } \\
\text { the surgical procedure. }\end{array}$ & $\begin{array}{l}\text { Local infiltration of the surgical site at the end of surgery } \\
\text { was specified as } 20-30 \mathrm{~mL} \text { (beneath external oblique } \\
\text { fascia) of } 0.5 \% \text { bupivacaine. Standard analgesic medication } \\
\text { consisted of } 500 \mathrm{mg} \text { naproxen (bid) for } \\
3 \text { days and then as needed. If inadequate, a combination } \\
\text { of } 50 \mathrm{mg} \text { tramadol and } 500-650 \mathrm{mg} \text { acetaminophen was } \\
\text { administered every } 4 \text { hours, as needed. If still inadequate, } \\
5 \mathrm{mg} \text { oxycodone and } 500-650 \mathrm{mg} \text { acetaminophen was } \\
\text { administered every } 4 \text { hours, as needed. }\end{array}$ \\
\hline Post-TKA & $\begin{array}{l}\text { Sedation with midazolam } \\
(0.05 \mathrm{mg} / \mathrm{kg} \text { titrated to effect) } \\
\text { or propofol }(25-75 \mu \mathrm{g} / \mathrm{kg} / \mathrm{h}) \\
\text { infusion. Use of PCA/PCEA } \\
\text { to maintain pain at rest at } \\
\leq 4 \text { on the I I-point NRS. }\end{array}$ & $\begin{array}{l}\text { Sedation with midazolam } \\
(0.05 \mathrm{mg} / \mathrm{kg} \text { titrated to effect) or } \\
\text { propofol }(25-75 \mu \mathrm{g} / \mathrm{kg} / \mathrm{h}) \text { infusion. } \\
\text { Anesthesia during the TKA was } \\
\text { provided by epidural, spinal, } \\
\text { or combined spinal/epidural } \\
\text { analgesia with local anesthetic } \\
\text { and hydromorphone or fentanyl. }\end{array}$ & $\begin{array}{l}\text { Use of peripheral nerve block was allowed for the first } \\
36 \text { hours postsurgery. Patients then switched to oral analgesia } \\
5 \text { mg hydrocodone bitartrate/500 mg acetaminophen tablets } \\
\text { every 4-6 hours as needed; or oxycodone/acetaminophen } \\
\text { (up to the maximum dose) and/or intravenous opioid PCA } \\
\text { (morphine, hydromorphone, fentanyl) depending on the site's } \\
\text { standard care. PCA/PCEA was used to maintain pain at rest } \\
\text { at } \leq 4 \text { on the II-point NRS. After discontinuation of the } \\
\text { epidural, oral warfarin, or low molecular weight heparin was } \\
\text { used to avoid deep venous thrombosis prophylaxis. }\end{array}$ \\
\hline Posthysterectomy & General anesthesia & $\begin{array}{l}\text { Supplemental analgesia medication } \\
\text { consisted of parenteral morphine } \\
\text { (or similar opioid agent) by } \\
\text { PCA pump, which was available } \\
\text { immediately after surgery. For } \\
\text { analgesia during the period before } \\
\text { PCA was started, opioid analgesic } \\
\text { was given by bolus injections. }\end{array}$ & $\begin{array}{l}\text { Parenteral morphine (or similar opioid analgesic agent) } \\
\text { was administered by PCA, as soon as possible postsurgery. } \\
\text { Opioid analgesics were also administered by bolus } \\
\text { injection, if required. If insufficient, additional opioid } \\
\text { analgesia was administered by bolus injection. If opioid } \\
\text { analgesia was inadequate or not well tolerated during } \\
\text { the period when PCA was used, NSAID (naproxen, } \\
\text { ibuprofen, diclofenac, ketorolac, or ketoprofen) and/or } \\
\text { acetaminophen was added or substituted as appropriate. }\end{array}$ \\
\hline
\end{tabular}

Abbreviations: bid, twice daily; IHR, inguinal hernia repair; NRS, numerical rated scale; NSAID, nonsteroidal anti-inflammatory drug; PCA, patient-controlled analgesia; PCEA, patient-controlled epidural analgesia; TKA, total knee arthroplasty.

pain were asked to complete the Neuropathic Pain Symptom Inventory (NSPI) questionnaire. ${ }^{13}$

The total cumulative dose and total daily dose of opioids, calculated as mg of oral morphine equivalent, were determined and included post-IHR opioids administered by any route.

\section{Safety measures}

Adverse events (AEs), safety, tolerability, and prespecified wound complications were evaluated and monitored throughout the trial.

\section{Statistical analysis}

A sample size of 100 patients per group was calculated to provide $90 \%$ power (two-sided $\alpha=0.05$ ) to detect a treatment effect of 1.0 on the pain NRS, assuming a standard deviation (SD) of 2.2. Efficacy analyses were carried out in the modified intent-to-treat population, defined as all randomized patients who were administered presurgery medications, had no surgical or anesthetic complications, and for whom at least one postbaseline safety evaluation was obtained. The primary endpoint analyses were conducted using analysis of variance with treatment and center included in the models and utilized Hochberg's multiple comparisons adjustment.

Safety analyses were conducted on all randomized patients who received at least one dose of study medication using descriptive statistics.

\section{Post-TKA trial}

\section{Patients}

The post-TKA trial was conducted at 24 sites in the US between May 2007 and December 2008 (NCT00442546). Patients were males and females aged 18-80 years with osteoarthritis undergoing elective TKA. Patients undergoing revision, unicompartmental, or bilateral TKA, or who had a planned second TKA at the time of the elective TKA procedure were excluded. Choice of anesthesia (spinal or epidural anesthesia) was determined by the individual standard of care at each center.

\section{Treatment}

Patients were randomized via a computer-generated 1:1:1 ratio to one of three arms: oral pregabalin $150 \mathrm{mg} / \mathrm{d}$ 
(75 mg bid) or $300 \mathrm{mg} / \mathrm{d}$ (150 mg bid), or placebo (bid). Patients received two preoperative treatment doses at 12 hours and 2 hours before surgery and continued treatment (bid dosing) for 6 weeks post-TKA (Figure 1). Details of rescue medications allowed are shown in Table 1.

\section{Efficacy outcome measures}

The primary efficacy measure was mean worst pain over the past 24 hours, assessed 48 hours post-TKA using the pain NRS from the mBPI-sf.

Secondary measures of pain included worst, average, and current pain intensity assessed 72 hours post-TKA. Passive and active flexion range of motion (ROM) of the operated knee were measured at baseline, and at weeks 2, 4, and 6 (or early termination) post-TKA. Continued pain in the area of surgery was assessed by telephone at 3 and 6 months post-TKA.

The total cumulative dose and total daily dose of opioids, calculated as mg of oral morphine equivalent, were determined and included post-TKA opioids administered by any route.

\section{Safety measures}

AEs, safety, tolerability, and prespecified wound complications were evaluated and monitored throughout the trial.

\section{Statistical analysis}

A sample size of 100 patients per group was calculated to provide $90 \%$ power (two-sided $\alpha=0.05$ ) to detect a treatment effect of 1.0 on the pain NRS, assuming a standard deviation (SD) of 2.2. Efficacy analyses were carried out in the modified intent-to-treat population, defined as all randomized patients who were administered presurgery medications, had no surgical or anesthetic complications, and for whom at least one postbaseline safety evaluation was obtained. The primary endpoint analyses were conducted using analysis of variance with treatment and center included in the models. As a result of prespecified interim analyses, the trial was terminated early owing to the primary outcome measure (mean pain over the previous 24 hours, assessed 48 hours post-TKA) not being significantly improved with pregabalin as compared with placebo.

Safety analyses were conducted on all randomized patients who received at least one dose of study medication using descriptive statistics.

\section{Posthysterectomy trial Patients}

The posthysterectomy trial was conducted at 37 sites in Canada, the Czech Republic, Hong Kong, South Africa,
Spain, Sweden, Thailand, the UK, and the US between June 2007 and October 2010 (NCT00468845). Patients were females aged 25-70 years undergoing elective abdominal hysterectomy using a transverse incision with or without bilateral salpingo-oophorectomy under general anesthesia. Patients having vaginal hysterectomy or additional procedures to the abdominal hysterectomy (such as those involving the bladder) were excluded. Use of wound infiltration using local anesthetics was not controlled across the study centers.

\section{Treatment}

Patients in the posthysterectomy trial were randomized via a computer-generated 1:1:1 ratio to one of three arms: oral pregabalin $150 \mathrm{mg} / \mathrm{d}(75 \mathrm{mg}$ bid) or $300 \mathrm{mg} / \mathrm{d}(150 \mathrm{mg}$ bid), or placebo (bid). Patients received two preoperative treatment doses at 12 hours and 2 hours before surgery and continued treatment (bid dosing) for 4 weeks postsurgery (Figure 1). Details of rescue medications allowed are shown in Table 1.

\section{Efficacy outcome measures}

The primary efficacy measure was mean worst pain over the past 24 hours, assessed 24 hours posthysterectomy using the pain NRS from the mBPI-sf.

Secondary measures of pain included worst and current pain intensity assessed 72 hours posthysterectomy and severity of movement-related pain (sitting and forced expiration) assessed up to 72 hours postsurgery. Continued pain in the area of surgery was assessed by telephone at 3 and 6 months posthysterectomy.

The total cumulative dose and total daily dose of opioids, calculated as mg of oral morphine equivalent, were determined and included post-TKA opioids administered by any route.

\section{Safety measures}

AEs, safety, tolerability, and prespecified wound complications were evaluated and monitored throughout the trial.

\section{Statistical analysis}

A sample size of 100 patients per group was calculated to provide $90 \%$ power (two-sided $\alpha=0.05$ ) to detect a treatment effect of 1.0 on the pain NRS, assuming a standard deviation (SD) of 2.2. Efficacy analyses were carried out in the modified intent-to-treat population, defined as all randomized patients who were administered presurgery medications, had no surgical or anesthetic complications, 
and for whom at least one postbaseline safety evaluation was obtained. The primary endpoint analyses were conducted using analysis of variance with treatment and center included in the models and a salpingo-oophorectomy stratification of the data. In addition, a weighted $z$-score test ${ }^{14}$ was used to compare the pregabalin and placebo groups for the primary efficacy endpoint, using the following weights: square root (137/300) for prior-to-interim data and square root (163/300) for postinterim data.

Safety analyses were conducted on all randomized patients who received at least one dose of study medication using descriptive statistics.

\section{Results}

\section{Post-IHR trial}

\section{Patients}

In total, 425 patients were randomized to treatment, and approximately $96 \%$ of these patients completed treatment (Figure 2). Patient demographics were similar between treatment groups (Table 2).

\section{Primary endpoint}

There was no difference between pregabalin and placebo treatment groups with respect to the primary endpoint of mean worst pain score over the past 24 hours, assessed at 24 hours post-IHR. The least squares mean difference between $300 \mathrm{mg} / \mathrm{d}$ pregabalin and placebo was -0.7 (95\% confidence interval $[\mathrm{CI}]=-1.4,-0.1 ; P=0.033$; Hochberg adjusted $P=0.067$ ).

\section{Secondary endpoints}

Pain

There was no difference between the pregabalin and placebo treatment groups for any measure of pain intensity (worst pain, average pain, current pain) at 72 hours post-IHR (Table 3). Continued pain in the area of surgery at 1 month post-IHR was reported by 20,24 , and 19 patients in the 50 , 150 , and $300 \mathrm{mg} / \mathrm{d}$ pregabalin groups, respectively, versus 26 patients in the placebo group. Patients who reported continued pain were asked to complete the NSPI. ${ }^{13}$ Mean (SD) total NSPI scores were similar between the pregabalin groups $(50 \mathrm{mg} / \mathrm{d}=0.03[0.03] ; 150 \mathrm{mg} / \mathrm{d}=0.03[0.05]$; $300 \mathrm{mg} / \mathrm{d}=0.05$ [0.04]) and the placebo group (0.04 [0.04]). Fewer patients reported continued pain at 3 months post-IHR, and by 6 months post-IHR, only 1 participant in each of the pregabalin groups reported continued pain compared with 0 in the placebo group.

Patients reported less movement-related pain (caused by sitting, walking, or coughing) at 1 hour post-IHR with $300 \mathrm{mg} / \mathrm{d}$ pregabalin, but not with 50 or $150 \mathrm{mg} / \mathrm{d}$ pregabalin, compared with placebo (Figure 3). Most movementrelated pain outcomes at 2 and 48 hours post-IHR were not

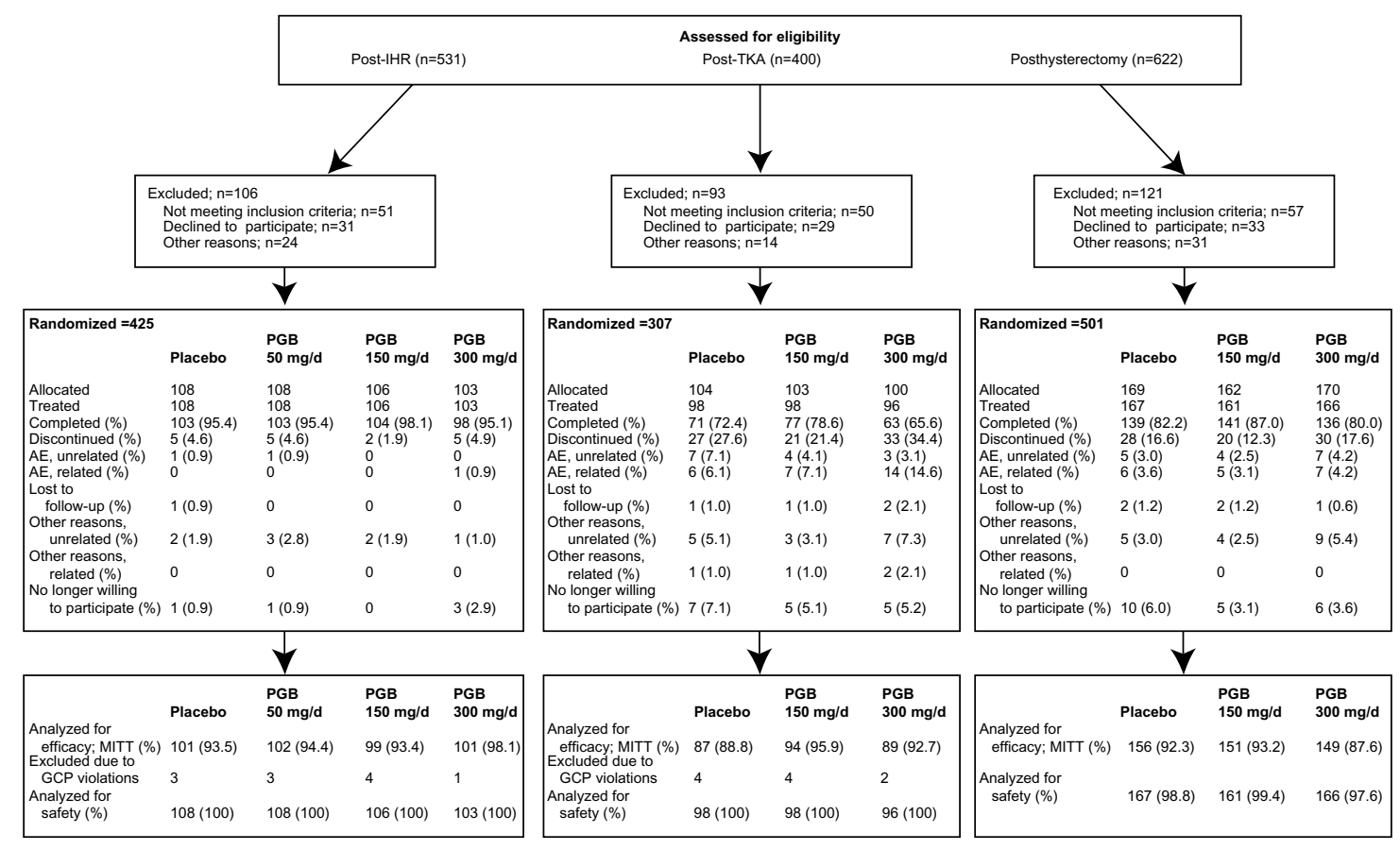

Figure 2 Participant disposition.

Abbreviations: AE, adverse event; GCP, good clinical practice; IHR, inguinal hernia repair; MITT, modified intent-to-treat population; PGB, pregabalin; TKA, total knee arthroplasty. 

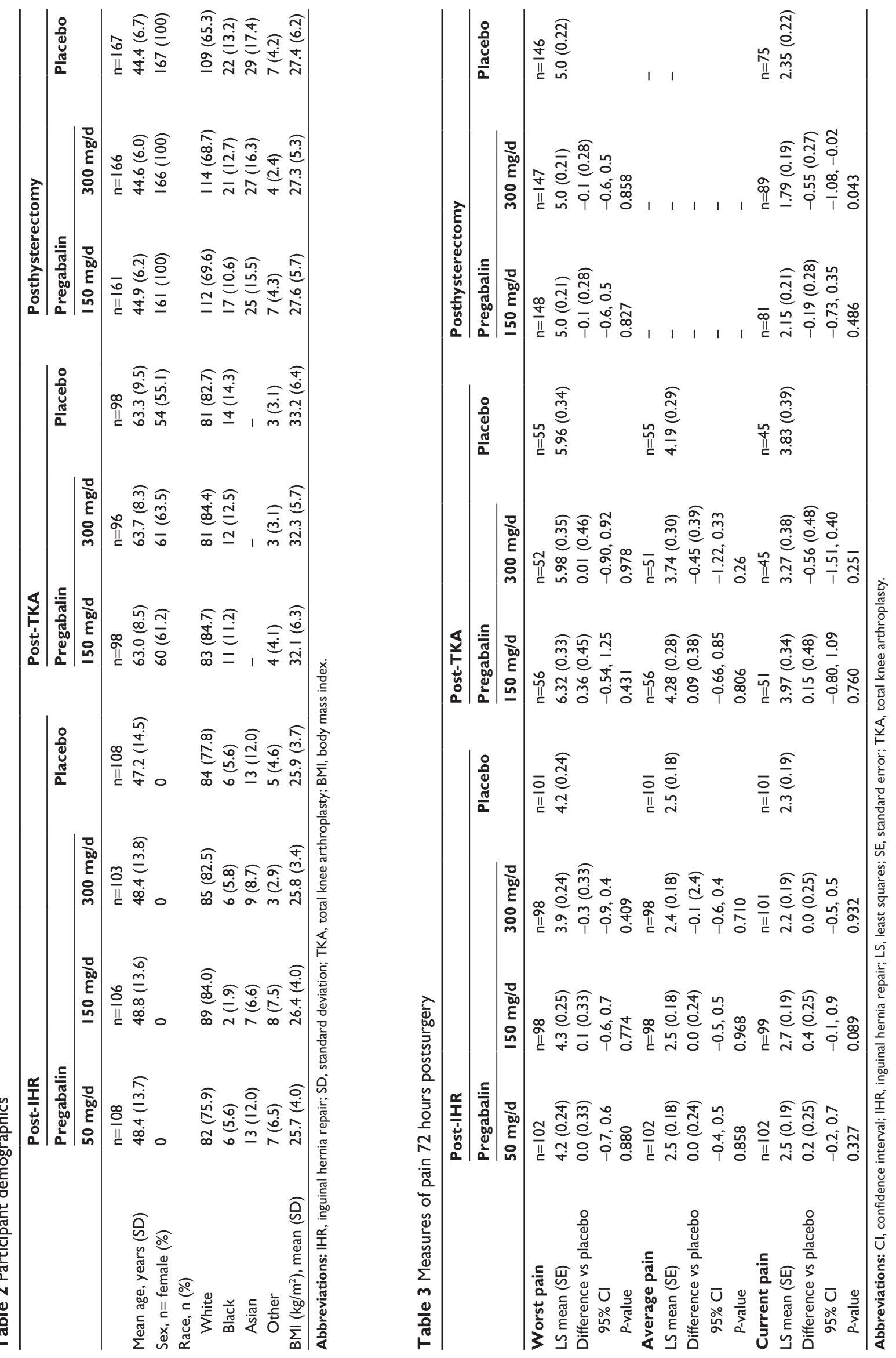

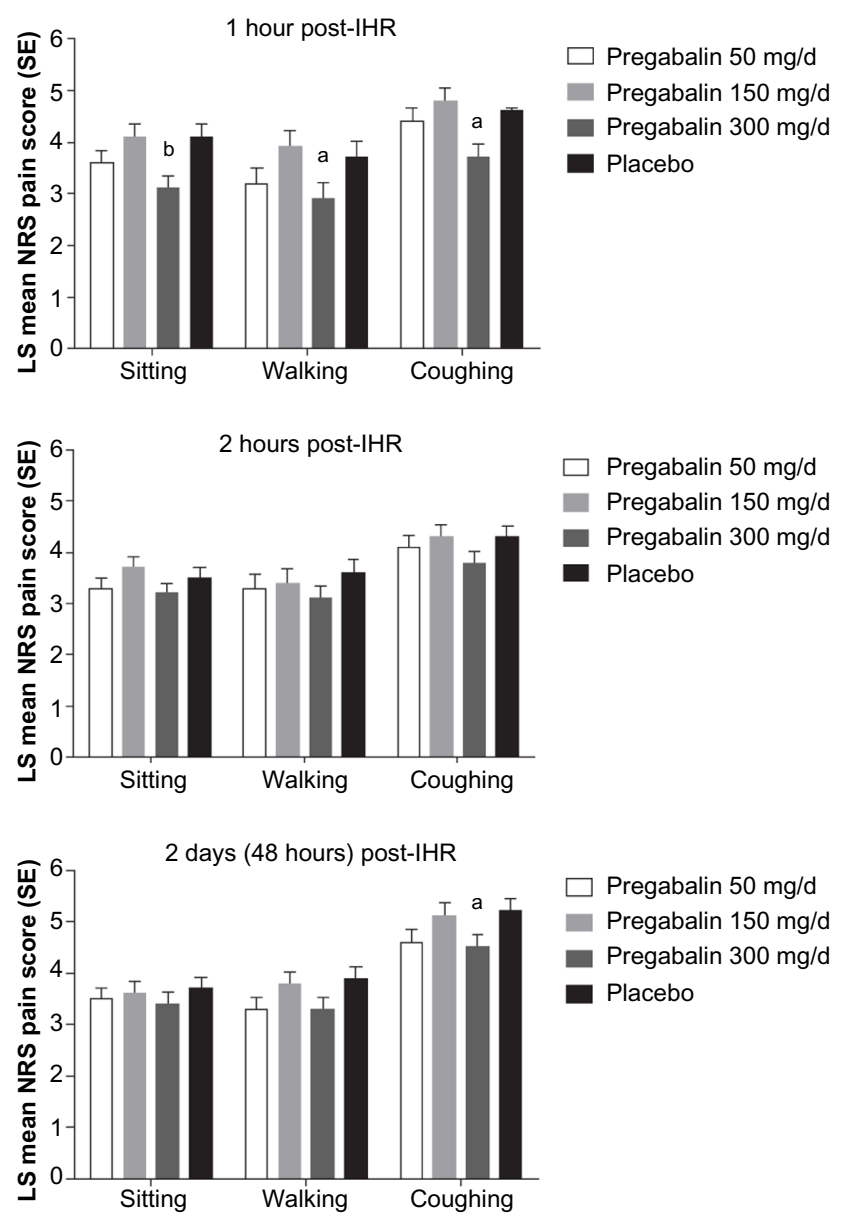

Figure 3 Movement-related pain (numerical rated scale) at I hour, 2 hours, and 2 days post-IHR.

Notes: ${ }^{a} P$-value vs placebo $<0.05$; ${ }^{b} P$-value vs placebo $<0.01$. Data for 3 hours and Day 4, 5, 6, 7 postsurgery and at end of treatment not shown (all endpoints not significant).

Abbreviations: IHR, inguinal hernia repair; LS, least squares; NRS, numerical rated scale; SE, standard error.

significantly different with pregabalin, including $300 \mathrm{mg} / \mathrm{d}$, compared with placebo.

\section{Opioid use}

The total cumulative opioid requirement at 24 hours post-IHR was decreased by $41 \%(P=0.035)$ and by $59 \%(P=0.002)$ in patients receiving 150 and $300 \mathrm{mg} / \mathrm{d}$ pregabalin, respectively, compared with placebo (Table 4). Cumulative opioid use was lower for the pregabalin $300 \mathrm{mg} / \mathrm{d}$ group compared with placebo for each of the first 7 days post-IHR (all $P<0.05$ ).

\section{Adverse events}

Treatment-emergent AEs (all-causality) occurring in $\geq 10 \%$ of any treatment group are summarized in Table 5. The most frequently reported AEs across all treatment groups were constipation, nausea, fatigue, dizziness, and somnolence. The majority of all AEs were mild to moderate in intensity.

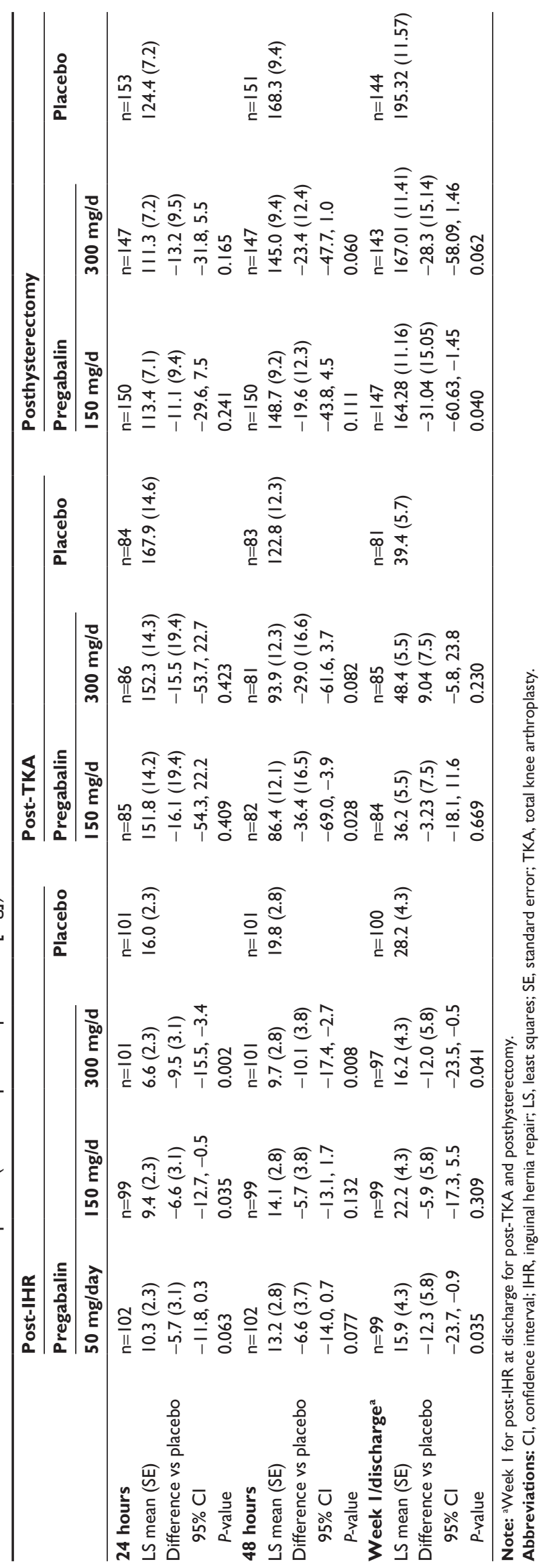




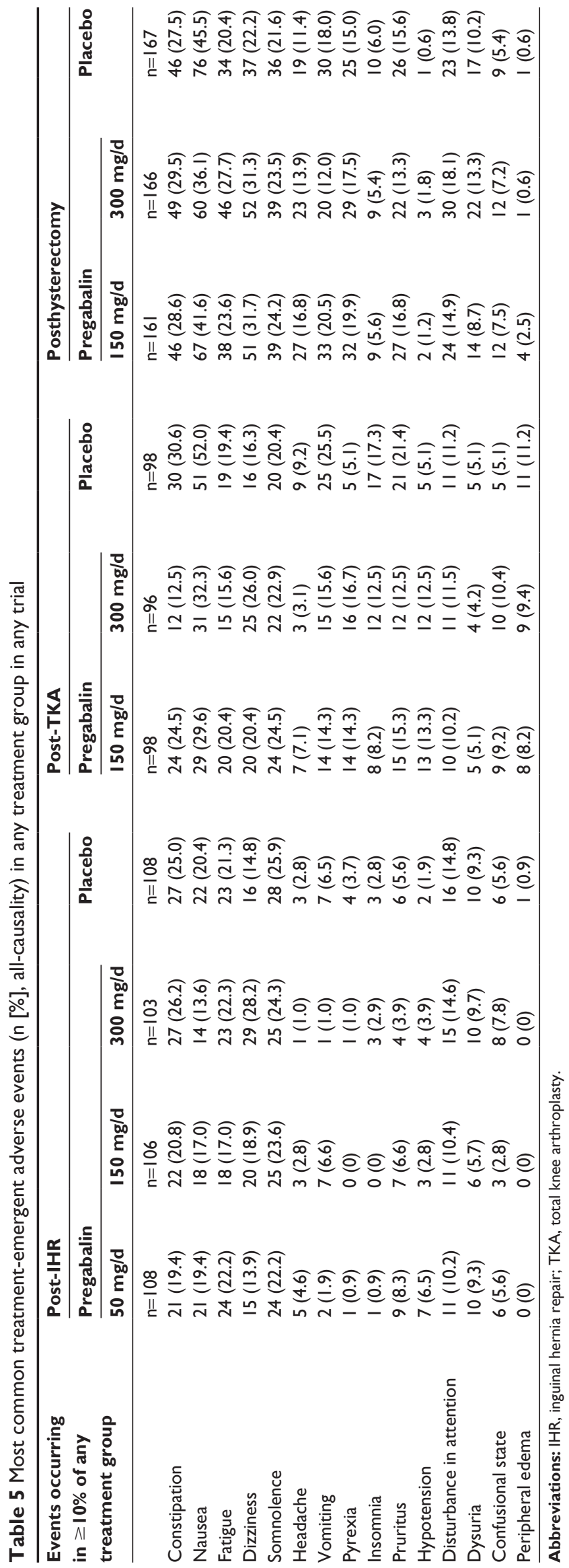

\section{Post-TKA trial}

\section{Patients}

In total, 307 patients were randomized to treatment, and approximately $69 \%$ of these patients completed treatment (Figure 2). Patient demographics were similar between treatment groups (Table 2).

\section{Primary endpoint}

There was no difference between the pregabalin and placebo treatment groups with respect to the primary endpoint of mean worst pain score over the past 24 hours, assessed at 48 hours post-TKA. The least squares mean difference between $300 \mathrm{mg} / \mathrm{d}$ pregabalin and placebo was -0.34 (95\% CI $=-1.07,0.39 ; P=0.362)$.

\section{Secondary endpoints \\ Pain}

There was no difference between the pregabalin and placebo treatment groups for any measure of pain intensity (worst pain, average pain, current pain) at 72 hours post-TKA (Table 3 ). The incidence of persistent pain at 3 months $(300 \mathrm{mg} / \mathrm{d}$ pregabalin $=22 / 59[37 \%]$; placebo $=27 / 61[44 \%])$ and at 6 months (300 mg/d pregabalin $=15 / 62$ [24\%]; placebo $=14 / 61$ [23\%]) post-TKA was similar between treatment groups, though only two-thirds of patients in each group were assessed owing to early termination of the trial. The rate of early termination of patients did not differ between groups.

Passive ROM for the operated knee was greater for the $300 \mathrm{mg} / \mathrm{d}$ pregabalin group compared with placebo at 24 hours (difference from placebo $=6.532^{\circ} ; P=0.015$ ), 72 hours (difference $=7.135^{\circ} ; P=0.006$ ), 96 hours (difference $=11.173^{\circ} ; P=0.008$ ), and 120 hours (difference $=17.941^{\circ} ; P=0.004$; Figure 4 ) post-TKA. There was also a significant difference from placebo at discharge (difference $=4.407^{\circ} ; P=0.022$ ) and at week 4 post-TKA (difference $=5.771^{\circ} ; P=0.018$; Figure 4). Passive ROM at most prespecified time points did not significantly differ between $150 \mathrm{mg} / \mathrm{d}$ pregabalin and placebo at most time points. Active ROM (upon flexion) was significantly greater in the $300 \mathrm{mg} / \mathrm{d}$ pregabalin group compared with placebo only at week 4 (difference $=5.32^{\circ} ; 95 \% \mathrm{CI}=0.20$, $10.43 ; P=0.042)$. At week 6 , all treatment groups had least squares (LS) mean ROM $>90^{\circ}$ on passive flexion (LS mean standard error [SE]: $150 \mathrm{mg} / \mathrm{d}$ pregabalin $=110.32^{\circ}$ [1.63]; $300 \mathrm{mg} / \mathrm{d}$ pregabalin $=111.35^{\circ}[1.88]$; placebo $=108.94^{\circ}$ [1.85]) and on active flexion (LS mean [SE]: $150 \mathrm{mg} / \mathrm{d}$ pregabalin $=105.35^{\circ}[1.85] ; 300 \mathrm{mg} / \mathrm{d}$ pregabalin $=106.25^{\circ}$ [2.14]; placebo $=103.98^{\circ}[2.05]$ ). 


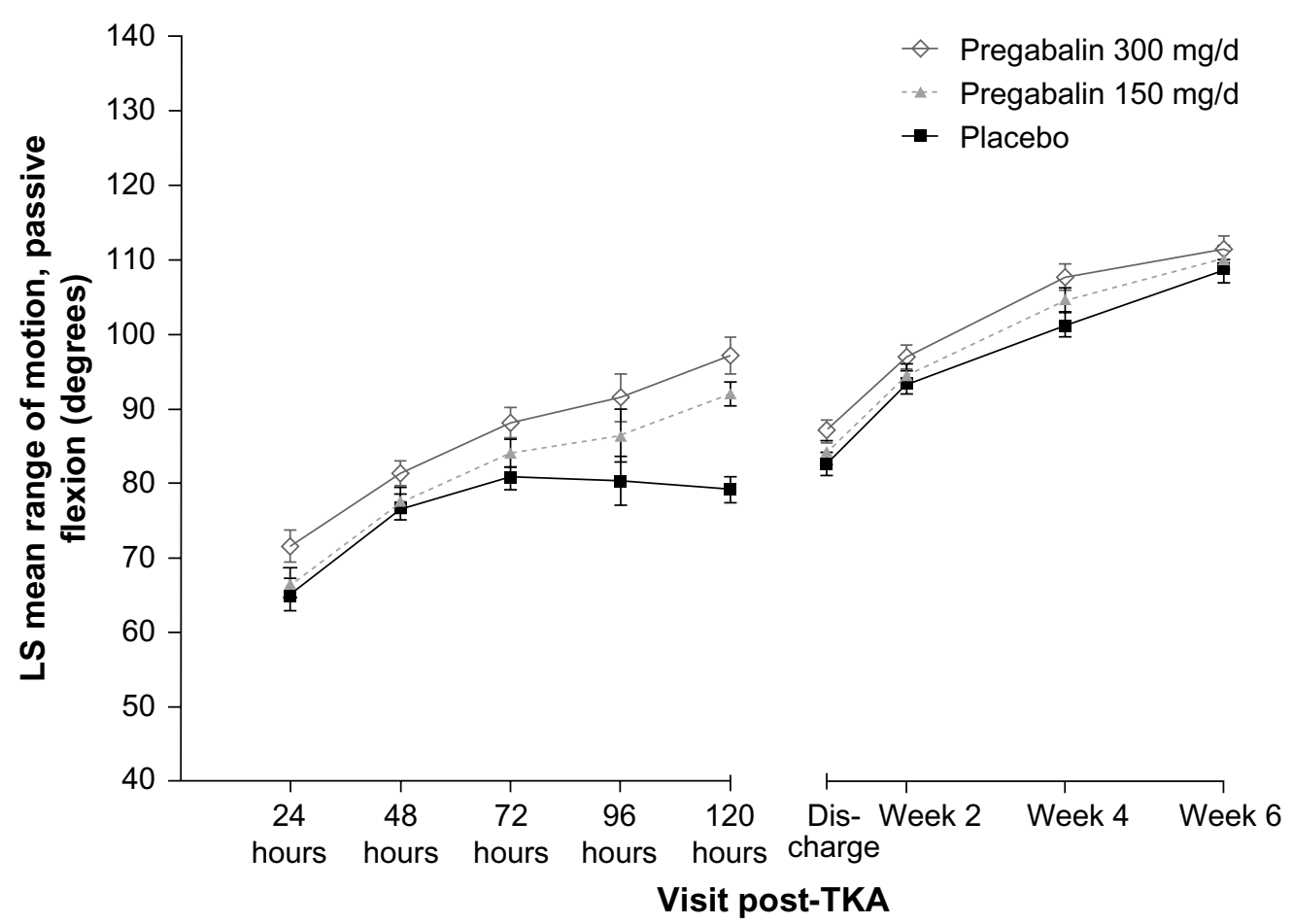

Figure 4 Passive range of motion of the operated knee post-TKA.

Notes: Pregabalin $150 \mathrm{mg} / \mathrm{d}$ vs placebo; $P<0.05$ at 120 hours post-TKA. Pregabalin $300 \mathrm{mg} / \mathrm{d}$ vs placebo; $P<0.0 \mathrm{I}$ at 72,96 , and I20 hours post-TKA. $P<0.05$ at 24 hours, at discharge, and at Week 4 post-TKA.

Abbreviations: LS, least squares; TKA, total knee arthroscopy.

\section{Opioid use}

The cumulative opioid requirement at 48 hours post-TKA was reduced by $30 \%(P=0.028)$ and by $25 \%(P=0.082)$ for the 150 and $300 \mathrm{mg} / \mathrm{d}$ pregabalin groups, respectively, compared with placebo (Table 4).

\section{Adverse events}

Treatment-emergent AEs (all-causality) occurring in $\geq 10 \%$ of any treatment group are summarized in Table 5. The most frequently reported AEs across all treatment groups were constipation, nausea, fatigue, dizziness, somnolence, and vomiting. The majority of all AEs were mild to moderate in intensity.

\section{Posthysterectomy trial}

\section{Patients}

In total, 501 patients were randomized to treatment, and approximately $83 \%$ of these patients completed treatment (Figure 2). Patient demographics were similar between treatment groups (Table 2). Overall, $89 \%, 95 \%$, and $92 \%$ of patients were premenopausal in the $150 \mathrm{mg} / \mathrm{d}$ pregabalin, $300 \mathrm{mg} / \mathrm{d}$ pregabalin, and placebo treatment groups, respectively.

\section{Primary endpoint}

There was no difference between the pregabalin and placebo treatment groups with respect to the primary endpoint of mean worst pain score over the past 24 hours, assessed at 24 hours posthysterectomy. The least squares mean difference between $300 \mathrm{mg} / \mathrm{d}$ pregabalin and placebo was $-0.2(95 \% \mathrm{CI}$ $=-0.66,0.31$; weighted $z$-score $=-0.721 ; P=0.471$ ).

\section{Secondary endpoints}

Pain

There was no significant difference between the pregabalin and placebo treatment groups for most measures of pain intensity (worst pain, average pain, current pain) at 72 hours posthysterectomy (Table 3 ). Likewise, there were no significant differences in the incidence of chronic pain at 3 months $(300 \mathrm{mg} / \mathrm{d}$ pregabalin $=22 / 126[18 \%]$; placebo $=14 / 137$ $[10 \%])$ or at 6 months $(300 \mathrm{mg} / \mathrm{d}$ pregabalin $=8 / 126[6 \%]$; placebo $=6 / 138[4 \%]$ ) posthysterectomy.

There was no significant difference between the pregabalin and placebo treatment groups in movementrelated pain caused by sitting or by forced expiration up to 72 hours posthysterectomy (data not shown).

\section{Opioid use}

The cumulative total opioid requirement, in mg-based morphine equivalents, was significantly lower for 150 $\mathrm{mg} / \mathrm{d}$ pregabalin compared with placebo at discharge (LS 
mean difference $=-31.04$ [15.05] mg; $P=0.040$ ), but not for pregabalin $300 \mathrm{mg} / \mathrm{d}$ versus placebo (Table 4).

\section{Adverse events}

Treatment-emergent AEs (all-causality) occurring in $\geq 10 \%$ of any treatment group are summarized in Table 5. The most frequently reported AEs across all treatment groups were constipation, nausea, fatigue, dizziness, and somnolence. The majority of all AEs were mild to moderate in intensity.

\section{Discussion}

In each of the three trials presented here, there was no significant difference between pregabalin and placebo with respect to the primary endpoint of mean worst pain after surgery (at 24 hours post-IHR and posthysterectomy, and at 48 hours post-TKA). Many secondary measures of pain also failed to demonstrate efficacy of pregabalin compared with placebo. Minimal improvements over placebo in functional/ movement-related pain were evident with $300 \mathrm{mg} / \mathrm{d}$ pregabalin in the post-IHR and post-TKA trials. There was also some evidence of an opioid-sparing effect with pregabalin in each trial, which is consistent with findings from a previous meta-analysis of pregabalin trials for the treatment of postoperative pain. ${ }^{15}$

The most frequently reported AEs with pregabalin in all three trials were nausea, dizziness, somnolence, constipation, and fatigue. The majority of AEs were mild to moderate in severity. Some AEs may be related to general and regional anesthesia (eg, dizziness, nausea, and vomiting), although dizziness was reported more frequently in pregabalin patients than in those receiving placebo across all three trials. Overall, the AEs reported here are consistent with those commonly reported in randomized controlled trials of pregabalin for other indications, and no new safety issues were identified. ${ }^{16}$

Previous clinical trials of $\alpha_{2} \delta$ ligands for postoperative pain, using surgical models similar to those presented here, have yielded mixed results. For example, a preoperative dose of 1,200 mg gabapentin was shown to reduce pain scores and opioid consumption posthysterectomy. ${ }^{17}$ Gabapentin has also been shown to reduce the intensity of acute pain and opioid use following IHR. ${ }^{18}$ Pregabalin has also demonstrated some efficacy for the treatment of postoperative pain. For example, perioperative administration of pregabalin, in conjunction with celecoxib, reduced opioid intake and decreased neuropathic pain scores at 3 and 6 months following TKA. ${ }^{5}$ Likewise, preoperative administration of $300 \mathrm{mg}$ pregabalin reduced pain scores and opioid consumption following total, or subtotal, hysterectomy with or without salpingo-oophorectomy. ${ }^{7}$ In contrast, however, pre- and perioperative administration of pregabalin in conjunction with either paracetamol, or paracetamol and dexamethasone, did not reduce posthysterectomy pain levels or opioid consumption. ${ }^{11}$

The three studies presented here were each large, controlled, randomized trials with multiple pain-related endpoints. All three studies failed to meet their primary, prespecified efficacy endpoint. However, limitations related to the design of these trials should be taken into consideration. Specifically, the prespecified primary endpoint of worst pain over the past 24 hours may not be the most sensitive measure of postoperative pain. Patients were asked to recall worst pain at a point in time at which their pain may have been at its worst level, or may have receded, and current pain experience may have influenced their recall. Indeed, given the complex nature of the subjective experience of pain, the debate regarding valid and reliable measures of acute pain, particularly in the postoperative setting, is ongoing. ${ }^{19,20}$

Additionally, in all three studies, the anesthetic and postoperative analgesic techniques used at each investigational site were at the discretion of the physician. Table 1 demonstrates the vast variability of preoperative, intraoperative, and postoperative analgesics that each study protocol allowed. Analgesic adjuvants such as nonsteroidal antiinflammatory drugs and local anesthetics have significant efficacy against postoperative pain ${ }^{21,22}$ and may not have been used equally in the pregabalin and placebo groups in the three trials. Likewise, intraoperative anesthetic techniques (especially nerve blocks) can have a significant impact on the postoperative pain experience and may not have been equally distributed between treatment groups. Larger-scale multicenter clinical trials, such as the ones reported here, will inevitably incorporate such variations in surgical technique, anesthetic practice, perioperative pain management, and data collection techniques. Such variations may have acted as confounding factors in the primary efficacy analyses and may have contributed, at least in part, to a lack of treatment effect with pregabalin. It should be noted, however, that the variation present in each of the three studies more accurately represents real-world clinical practice compared with a highly controlled clinical trial that places restrictions on the use of anesthetic/surgical techniques.

\section{Conclusion}

There was no significant difference between pregabalin and placebo with respect to the primary endpoint (worst pain 24/48 hours postsurgery) for any of the surgical models examined. 
However, there was suggestive evidence of efficacy for other secondary endpoints, such as pain upon movement in the post-IHR trial and ROM in the post-TKA trial. There was also evidence of a pregabalin-mediated opioid-sparing effect in each trial. Overall, further controlled studies are needed to fully investigate the potential pain-reducing benefit of pregabalin in the postoperative setting.

\section{Acknowledgments}

These studies were sponsored by Pfizer Inc. Editorial/medical writing support was provided by Brenda Meyer and Matt Soulsby, PhDs, of Engage Scientific Solutions and was funded by Pfizer Inc. The authors wish to thank Professor Henrik Kehlet for his time and contributions to the discussions of the post-IHR data, and for his input during the early stages of the development of this manuscript. They would also like to thank the following Principal Investigators at each of the study sites.

\section{Post-IHR trial}

Australia: K Khor; Canada: S Farmer, S Ganapathy, R Truchon; India: R Ardhanari, D Duttaroy, B Kalambe, AK Saxena; Spain: AO Castro, SG del Valle y Manzano, CP Hernandez, C Sancho; Sweden: P Brunkwall, A Gupta, M Hedberg, L Molinder, L Ruthstrom; USA: JA Boskind, JE Chelly, ME Cooper, JD Corbitt Jr, A Doraiswamy, JS Garza, P Glass, RK Jones, MG Kent, HS Minkowitz, MW Morris, WT Nicholson, NK Singla, SK Singla, R Thakur, WC Wood.

\section{Post-TKA trial}

WS Bowen, A Buvanendran, KA Candiotti, WA Cenac, JE Chelly, JS Gimbel, DW Griffin, DR Lionberger, MA McShane, LS Matthews, BD Nicholson, AC Ong, J Parvizi, BD Springer, MB Stachniw, M Urban, DL Williams.

\section{Posthysterectomy trial}

Canada: F Bissonnette, E De Medicis, GS Hawboldt; Czech Republic: R Vlk; Hong Kong: TK Hung Chung, T Brake; South Africa: TJ De Villiers, JCJ Jurgens, D Lakha, JAR Matambo, L Reynders, T Smith; Spain: AO Castro, F Gilsanz Rodriguez, LM Torres, JC Tornero Tornero; Sweden: CBorgfeldt, A Gupta, J Zetterstrom; Thailand: P Chaudakshetrin, S Paiboonworachat, PR Yimyaem; UK: PM Barclay, PJ Dewart, LM MacKinnon Morrison, JP Thompson, PM Toozs-Hobson; USA: LA Arya, KA Candiotti, JE Chelly, JS Gimbel, HB Miller, HS Minkowitz, RL Shields, NK Singla, SK Singla, J Waters.

\section{Author contributions}

Drs N Singla, JE Chelly, DR Lionberger, and J Gimbel participated in the conduct of the study and contributed to data collection for one or more of the clinical trials. They each contributed to the interpretation of the data and were involved in drafting and reviewing the manuscript for intellectual content. Drs L Sanin, J Sporn, R Cheung, and L Knapp participated in the design and conduct of the study, interpretation of the data, and were involved in drafting and reviewing the manuscript for intellectual content. Dr B Parsons participated in the design of the study, interpretation of the data, and was involved in drafting and reviewing the manuscript for intellectual content. Dr R Yang conducted the prespecified and post hoc analyses, and participated in the interpretation of data, writing, and reviewing of the manuscript. All authors discussed the results, commented on the manuscript, reviewed and approved the final version of the manuscript for publication. Drs N Singla and B Parsons take responsibility for the integrity of the work as a whole, from inception to published article.

\section{Disclosure}

N Singla is the Chief Executive Officer of Lotus Clinical Research and serves as a member of the Medical Advisory Board at AcelRx Pharmaceuticals Inc. He has acted as paid consultant to other pharmaceutical companies, including Pfizer Inc. DR Lionberger is an employee of Aesculap Implant Systems and has acted as consultant to Aesculap Implant Systems, King Pharmaceuticals, Salient Technologies, Pfizer Inc., Smith and Nephew, and Alpharma Pharmaceuticals Inc. He holds research grants with Aesculap Implant Systems, Salient Technologies, and Pfizer Inc., and also has patent rights for Zimmer and Aesculap Implant Systems. J Gimbel is a principal investigator of clinical trials with Pfizer Inc., J\&J, Celgene, Array BioPharma Inc., Roche, Amgen, Purdue, Lilly, GlaxoSmithKline, Bristol-Myers Squibb, Daiiachi Sankyo, and QRxPharma, and has consulting agreements with Pfizer Inc., Array BioPharma Inc, and Adynxx Inc. L Sanin, J Sporn, R Yang, R Cheung, L Knapp, and B Parsons are all employees of Pfizer Inc., own Pfizer stock, and have Pfizer stock options. The authors report no other conflicts of interest in this work.

\section{References}

1. LYRICA [prescribing information]. New York: Pfizer Inc.; 2013.

2. LYRICA capsules [summary of product characteristics ]. New York: Pfizer Inc.;2014. Available from http://www.medicines.org.uk/emc/ medicine/14651/SPC/. Accessed October 10, 2014. 
3. Agarwal A, Gautam S, Gupta D, Agarwal S, Singh PK, Singh U. Evaluation of a single preoperative dose of pregabalin for attenuation of postoperative pain after laparoscopic cholecystectomy. Br J Anaesth. 2008;101:700-704.

4. Burke SM, Shorten GD. Perioperative pregabalin improves pain and functional outcomes 3 months after lumbar discectomy. Anesth Analg. 2010;110:1180-1185

5. Buvanendran A, Kroin JS, Della Valle CJ, Kari M, Moric M, Tuman KJ. Perioperative oral pregabalin reduces chronic pain after total knee arthroplasty: a prospective, randomized, controlled trial. Anesth Analg. 2010;110:199-207.

6. Hill CM, Balkenohl M, Thomas DW, Walker R, Mathe H, Murray G. Pregabalin in patients with postoperative dental pain. Eur J Pain. 2001;5: 119-124.

7. Ittichaikulthol W, Virankabutra T, Kunopart M, Khamhom W, Putarawuthichai P, Rungphet S. Effects of pregabalin on post operative morphine consumption and pain after abdominal hysterectomy with/ without salphingo-oophorectomy: a randomized, double-blind trial. J Med Assoc Thai. 2009;92:1318-1323.

8. Kim SY, Song JW, Park B, Park S, An YJ, Shim YH. Pregabalin reduces post-operative pain after mastectomy: a double-blind, randomized, placebo-controlled study. Acta Anaesthesiol Scand. 2011;55:290-296.

9. Turan A, Karamanlioğlu B, Memiş D, et al. Analgesic effects of gabapentin after spinal surgery. Anesthesiology. 2004;100:935-938.

10. Mathiesen O, Jacobsen LS, Holm HE, et al. Pregabalin and dexamethasone for postoperative pain control: a randomized controlled study in hip arthroplasty. Br J Anaesth. 2008;101:535-541.

11. Mathiesen O, Rasmussen ML, Dierking G, et al. Pregabalin and dexamethasone in combination with paracetamol for postoperative pain control after abdominal hysterectomy. A randomized clinical trial. Acta Anaesthesiol Scand. 2009;53:227-235.
12. Paech MJ, Goy R, Chua S, Scott K, Christmas T, Doherty DA. A randomized, placebo-controlled trial of preoperative oral pregabalin for postoperative pain relief after minor gynecological surgery. Anesth Analg. 2007;105:1449-1453.

13. Bouhassira D, Attal N, Fermanian J, et al. Development and validation of the Neuropathic Pain Symptom Inventory. Pain. 2004;108:248-257.

14. Fisher LD. Self-designing clinical trials. Stat Med. 1998;17:1551-1562.

15. Zhang J, Ho KY, Wang Y. Efficacy of pregabalin in acute postoperative pain: a meta-analysis. Br J Anaesth. 2011;106:454-462.

16. Zaccara G, Gangemi P, Perucca P, Specchio L. The adverse event profile of pregabalin: a systematic review and meta-analysis of randomized controlled trials. Epilepsia. 2011;52:826-836.

17. Turan A, Karamanlioglu B, Memis D, Usar P, Pamukcu Z, Ture M. The analgesic effects of gabapentin after total abdominal hysterectomy. Anesth Analg. 2004;98:1370-1373.

18. Sen H, Sizlan A, Yanarateş O, et al. The effects of gabapentin on acute and chronic pain after inguinal herniorrhaphy. Eur J Anaesthesiol. 2009;26:772-776

19. Gilron I, Jensen MP. Clinical trial methodology of pain treatment studies: selection and measurement of self-report primary outcomes for efficacy. Reg Anesth Pain Med. 2011;36:374-381.

20. Srikandarajah S, Gilron I. Systematic review of movement-evoked pain versus pain at rest in postsurgical clinical trials and meta-analyses: a fundamental distinction requiring standardized measurement. Pain. 2011;152:1734-1739.

21. Moote C. Efficacy of nonsteroidal anti-inflammatory drugs in the management of postoperative pain. Drugs. 1992;44(Suppl 5):14-29.

22. Straube S, Derry S, McQuay HJ, Moore RA. Effect of preoperative Cox-II-selective NSAIDs (coxibs) on postoperative outcomes: a systematic review of randomized studies. Acta Anaesthesiol Scand. 2005;49:601-613
Journal of Pain Research

\section{Publish your work in this journal}

The Journal of Pain Research is an international, peer-reviewed, open access, online journal that welcomes laboratory and clinical findings in the fields of pain research and the prevention and management of pain. Original research, reviews, symposium reports, hypothesis formation and commentaries are all considered for publication.

\section{Dovepress}

The manuscript management system is completely online and includes a very quick and fair peer-review system, which is all easy to use. Visit http://www.dovepress.com/testimonials.php to read real quotes from published authors. 